\title{
El SueÑo eVANescente de CiCERón: EL PARAÍSO DE LOS POLÍTICOS
}

Juan José Seguí Marco

Universitat de València

Resumen: En este artículo abordamos la propuesta que hace Cicerón en el capítulo conocido como «El Sueño de Escipión» de su libro «De re publica», donde enuncia un paraíso para las almas de los políticos más ilustres. Surgida en un momento de crisis de la República romana es un intento por crear un estímulo a los hombres honestos para salvar el Estado. Pese a su evanescencia, como la del régimen que intentó apuntalar, fue no obstante aprovechada por los emperadores para reforzar los fundamentos de su propio poder.

Palabras clave: Cicerón, Macrobio, república romana, pensamiento político, religión.

romana.

ABSTRACT: In this article we approach Cicero's proposal in the famous chapter 'The Dream of Scipio' in his book De re publica, where he states a paradise for the souls of the most illustrious politicians. The proposal came up at a time of crisis in the Roman Republic and it sought a stimulus to honest men to save the state. Despite its evanescence, the Roman emperors used it to strengthen the foundations of their own power.

Keywords: Cicero, Macrobius, Roman Republic, Political Thought, Roman Religion. 
$\mathrm{L}$ a obra más importante de reflexión política de Cicerón es, sin duda, su diálogo "De re publica». ${ }^{1}$ Fue escrito en el 53 a. C., en un momento muy especial de la vida del autor, cuando su carrera ya no estaba en el cénit, pero sí su madurez intelectual. ${ }^{2}$ Por desgracia el libro nos ha llegado incompleto. De sus seis capítulos solo conservamos con cierta amplitud los tres primeros, producto de un hallazgo tardío. ${ }^{3}$ Los dos siguientes se han perdido y lo poco que conocemos se debe a citas de otros autores, mientras el último, el llamado «Sueño de Escipión», que centra nuestro interés, ha sobrevivido de forma separada. ${ }^{4}$ No obstante, pese a estas amputaciones, la estructura y el sentido de la obra es claro. Algunos importantes personajes de la vida romana se reúnen para conversar sobre los sistemas de gobierno en los horti suburbani de Escipión Emiliano durante los tres días en que se celebraron las feriae Latinae del 129 a. C. El axioma de que la vida pública activa es la forma más excelsa si se asume desde la virtud (virtus) y la entrega al bien común (officium), muy superior a la que puede deparar el otium (I \$1-8) -una abierta crítica a la filosofía contemplativa y a los epicúreos-, configura el arranque y también el hilo conductor del libro que, tras algunos circunloquios, se encauza definitivamente hacia el análisis de los regímenes políticos. Cicerón

1. Las ediciones del libro son numerosísimas. Nosotros hemos utilizado las de K. Ziegler, De re publica, Teubner, Munich, 1969; P. SAmaranch, La República, Buenos Aires, 1970; F. CANCELli, Lo Stato, Mondadori, Florencia, 1979; R. PÉrez Delgado, La República, Aguilar, Madrid, 1979; E. Bréguet, La République, Les Belles Lettres, París, 1980; A. D’Ors, Sobre la República, Biblioteca Clásica Gredos, Madrid, 1984; J. Guillén, Sobre la República. Sobre las leyes, Tecnos, Madrid, 1986; C. W. Keyes, De re publica. De legibus, Loeb, Cambridge-Harvard, 1988; J. M. NúÑEz, La República y las leyes, Akal, Torrejón de Ardoz, 1989; J. M. Del Pozo, La República, Bernat Metge, Barcelona, 2006. La mejor recopilación de estudios sobre el libro hasta la fecha de su publicación es, sin duda, la de P. L. SCHMIDT, «Cicero 'De re publica': Die Forschung der letzten fünf Dezennien», $A N R W$ I, 1973, Berlín-Nueva York, pp. 262-333.

2. La bibliografía sobre Cicerón es inabarcable. Entre sus biografías destacamos las de M. Rambaud, Cicéron et l'histoire romaine, París, 1953; O. SEEL, Vox humana: ein Lesebuch aus Cicero, Stuttgart, 1963; L. Perelli, Il pensiero politico di Cicerone, Turín, 1964; E. SCHwart, Figuras del mundo antiguo, Madrid, 1966²; J. CARCopino, Les secrets de la correspondance de Cicéron, París, 1967; W. K. LACEY-W. J. G. Wilson, Res publica. Roman politics and society according to Cicero, Oxford, 1970; K. E. PetzHOLD, «Cicero und Historie», Chiron, 2, 1970, pp. 252 y ss.; P. BADILlo, Cicerón y el Imperio, Puerto Rico, 1976; S. L. Utchenko, Cicerón y su tiempo, Madrid, 1978; J. Guillén, Héroe de la libertad. Vida política de M. Tulio Cicerón, II vols., Salamanca, 1981; G. Boissier, Cicerón y sus amigos, México, 1986; P. GRIMAL, Cicerone, Nápoles, 1986; J.G.F. Powell, Cicero the Philosopher, Oxford 1995; J. M. Del Pozo, Cicerón: conocimiento y politica, Madrid, 1993; F. PINA, Marco Tulio Cicerón, Barcelona, 2005. Los rasgos generales del autor y la bibliografía especializada pueden consultarse fácilmente para el lector español en J. BAYET, Literatura Latina, Barcelona, 1982 (6ª), pp. 136-154; E. Bickel, Historia de la literatura romana, Madrid, 1987 (2a), passim; E. J. Kenney-W. V. Clausen (ed.), Historia de la literatura clásica, Madrid, 1989, II, pp. 261-301.

3. En 1819 el erudito italiano Angelo Mai lo encontró en la Biblioteca Vaticana en un palimpsesto, oculto bajo unos comentarios de los Salmos de San Agustín. Cf. F. CANCElli, loc. cit., pp. 12-15; A. D'Ors, loc. cit., p. 11.

4. Para esta parte hemos utilizado preferentemente las siguientes obras: P. BoYAnCÉ, Études sur le songe de Scipion, Limoges, 1936; A. Magariños, Cicerón. Sueño de Escipión, Madrid, 1943; R. ACUÑa, M. T. Cicerón. El sueño de Escipión, Universidad Nacional Autónoma de México, México D. F., 1989; W. HARRIS Stahl, Macrobius. Commentary on the Dream of Scipio, Nueva York, 1990; F. STOK, Cicerone. Il sogno di Scipione, Marsilio, Venecia, 1994²; F. Navarro, Macrobio. Comentario al Sueño de Escipión, Biblioteca Clásica Gredos, Madrid, 2006; J. Raventós, Macrobio. Comentarios al Sueño de Escipión, Ediciones Siruela, Madrid, 2005. 
repasa detenidamente las diferentes formas de organización de la vida pública, concluyendo que de las tres que identifica -la monárquica, la aristocrática y la democrática- la superior es aquella que las combina todas sin excesos (I $\$ 45$; II \$39). ${ }^{5}$ La materialización de este ideal se encuentra para el arpinate en el régimen republicano romano anterior a los Gracos (I \$46-47). ${ }^{6}$ Cicerón encuentra que la solución a la profunda crisis que vive su tiempo es el retorno a los valores y a las costumbres (mores maiorum) de la República primitiva, a la que erige en hito histórico, un ideal de gobierno que debe recuperarse. Cicerón es muy consciente de que las instituciones republicanas son incapaces por sí solas de conseguir rectificar una situación de conflicto permanente que aboca a la decadencia política. La figura transitoria de un princeps, un político sensato, cargado de experiencia y cualidades (rector rei publicae o rector civitatis), que respetando la ley y la costumbre fuera capaz de devolver la prosperidad a la vida pública, es para Cicerón la solución más acertada. ${ }^{7}$ Queda de este modo configurado el expediente teórico de que ciertos hombres egregios pueden prestar al estado servicios excepcionales en momentos de especial gravedad. Se trata, no obstante, de un princeps surgido entre los miembros del senado, los principales, los mandatarios supremos de la República, nombrado por y entre ellos. ${ }^{8}$

El autor consagra todo el capítulo siguiente a los orígenes y fundamentos de la República romana, pero antes subraya cómo sus logros no se deben a algún personaje singular en un momento determinado de su historia -como aconteció a los griegos-, sino que es el resultado de la entrega de muchos varones ilustres a lo largo de siglos (II $\$ 1$ ). Cicerón se solaza hablando del periodo que va desde Rómulo hasta los últimos reyes (II \$1-31), mostrando un extenso panorama de la monarquía romana, en el que contrasta la sabiduría del primer rey con la degeneración del último monarca. El advenimiento de la República vino a corregir una situación que había degenerado en tiranía (II \$26-27), y a consagrar el principio del equilibrio de poderes, con unos magistrados que detentaban desde entonces la potestad (potestas), un senado que obraba bajo el principio de su ascendencia (auctoritas) y un pueblo que elegía en libertad (libertas) (II \$32). Tras condensar la evolución institucional de la primitiva República, Cicerón exalta la concordia social (concordia

5. La misma idea la expresó antes Polibio, VI 3, 5-12, aunque inspirado en el ejemplo romano. Cf. P. Pedech, La méthode historique de Polybe, París, 1964, pp. 303-330. Una visión más heterogénea sobre su influencia en F. W. Walbank, A historical commentary on Polybius, I, Oxford, 1957, p. 635. No obstante, la tradición literaria es más antigua y está presente ya en Heródoto, III 80-82.

6. Cf. G. Boissier, loc. cit., pp. 22-23. Cf. G. Hinojo, «Los juicios de Cicerón sobre los Gracos», Studia Historica. Historia Antigua, 4-5, 1986-1987, pp. 101-109.

7. Sobre la interpretación de esta figura en la historiografía ciceroniana cf. F. CANCELLI, loc. cit., pp. 126-136 y E. BréGuet, loc. cit., I, pp. 128-142. También J. SANTA Cruz, «Notas sobre 'De republica' de Cicerón», Revista de estudios políticos, 139, 1965, pp. 155-172; I. RocA, «Bosquejo de una teoría política en la Roma clásica», Millars, 4, 1977, pp. 56-53; J. G. F. Powell, «The rector rei publicae of Cicero`s de Republica», Scripta Classica Israelica, 13, 1994, pp. 19-29; F. PinA, loc. cit., pp. 265-266.

8. Se ha discutido mucho si Cicerón estaba pensando en Pompeyo, en sí mismo, o en algún otro contemporáneo. Cf. J. Guillén, Héroe..., p. 125. 
ordinum) como un logro fundamental para alcanzar la optima res publica, que solo puede establecerse si existe justicia (iustitia) (II $\$ 42$ ). En el libro III uno de los interlocutores, Filón, consiente en adoptar un papel crítico, defendiendo el relativismo de la justicia, mientras su oponente, Lelio, en su papel de estoico propio de Cicerón, rechaza la injusticia, que la Roma republicana habría erradicado (III \$5) y la ley natural frente al relativismo (III \$9). ${ }^{9}$ Pese a su estado fragmentario, se intuye que los libros IV y V se ocupaban del político ideal, de su educación, de su papel en la ciudad como rector rerum publicarum $(\mathrm{V} \$ 4)$ y de su recompensa ante sus conciudadanos (V \$7). ${ }^{10}$

El último capítulo del libro, el conocido como «Sueño de Escipión», que centra nuestro interés, presenta unos rasgos particulares. Como si fuese un destino del que no podía escapar ninguna parte de «De re publica», la supervivencia del último capítulo fue resultado de una venturosa casualidad. A finales del siglo iv o principios de la siguiente centuria, Macrobio confeccionó un «Comentario al Sueño de Escipión de Cicerón», que incorporaba el texto original. El «Comentario» planteaba una reflexión al hilo de la obra del arpinate sobre algunas cuestiones que interesaban de forma muy especial a Macrobio, todas enfocadas desde teorías neoplatónicas. Se comprende que tanto por el despliegue de conocimientos de que hacía gala, como por el interés que presentaba esta parte de la obra ciceroniana, el opúsculo adquiriese gran prestigio, lo que garantizó su supervivencia hasta el punto de llegar a ejercer una gran influencia en el pensamiento europeo medieval y renacentista, ávido de este tipo de conocimientos, algo que se refleja en las múltiples reediciones que contribuyeron a salvar al menos esta parte de la obra ciceroniana. ${ }^{11}$

El libro VI de «De re publica» ofrece una presentación bien diferente al resto de capítulos -algo en lo que también sigue al modelo del diálogo platónico que tanto le inspira- pues Cicerón envuelve el último día del coloquio dentro de otro diálogo, este extraordinario. En efecto, Escipión Emiliano narra cómo al acostarse después de conversar con el rey Masinisa, al que visitaba en el curso de la III Guerra Púnica, le sobrevino un sueño en el que se le apareció Escipión el Africano. El vencedor de Aníbal no solo le reveló el destino (VI $\$ 11-12)$, sino que le instruyó sobre materias de gran trascendencia, tales como las recompensas que aguardan a los hombres eminentes en la otra vida (VI $\$ 13-16)$, las características del universo (VI \$17-18), el lugar que en él ocupa la Tierra (VI $\$ 19-20$ ), y el destino y la naturaleza del hombre (VI $\$ 21-26$ ). ${ }^{12}$ Cicerón traslada al lector, en esta parte final de su obra, a un mundo empíreo aunque en conexión con la realidad física, que así adquiere una dimensión diferente. El espacio extrasensorial no solo corona la vida humana sino que

9. Sobre la visión estoica ciceroniana cf. J. GuILlÉN, «La sabiduría y el sabio en Cicerón», Helmantica, 44, 1993, pp. 413-434.

10. Cf. E. BrÉguet, loc. cit., I, pp. 72-83.

11. Cf. F. Navarro, loc. cit., pp. 68-113; J. Raventós, loc. cit., p. 10.

12. Cf. E. Bréguet, loc. cit., I, pp. 83 y ss; J. Guillén, Héroe..., pp. 120-124; J. Raventós, loc. cit., pp. 16-20. 
también, a través de los sueños, la ilumina. La realidad, desde el pasado hasta el futuro, queda desvelada por ellos.

Entre toda la variedad de temas queremos centrar nuestra atención en el de la inmortalidad de las almas de los políticos, por tratarse del elemento de cierre de toda la construcción intelectual del arpinate. Donde mejor se condensa el concepto ciceroniano a este respecto es en el siguiente parágrafo:

Pero para que tú, Africano, estés más decidido en la defensa de la república, ten esto en cuenta: para todos los que hayan conservado la patria, la hayan asistido y aumentado, hay un cierto lugar determinado en el cielo, donde los bienaventurados gozan de la eternidad. Nada hay, de lo que se hace en la tierra, que tenga mayor favor cerca de aquel dios sumo que gobierna el mundo entero que las agrupaciones de hombres unidos por el vínculo del derecho, que son las llamadas ciudades. Los que ordenan y conservan estas, salieron de aquí y a este cielo vuelven (VI 13). ${ }^{13}$

Ante todo hay que indicar que Cicerón tampoco se muestra original en esta parte final de su libro. Su fuente primordial, la «República» de Platón, que con tanta fuerza le había inspirado su pensamiento, sigue siendo ahora el plectro para configurar el escenario onírico propicio a revelaciones extraordinarias, un cierre espectacular para la obra. ${ }^{14}$ En realidad el «Sueño de Escipión» ocupa el mismo lugar que guarda en el final del diálogo platónico la fábula de Er, hijo de Armenio, un soldado panfilio, que regresa de ultratumba para contar su experiencia. ${ }^{15}$ Ahora bien, mientras en el mito platónico el interés se dirige a mostrar los premios y los castigos reservados a las almas y a revelar la existencia de un círculo migratorio de los espíritus, en Cicerón solo se presta atención a una parte del mundo celestial en el que moran las ánimas de los hombres que se ocuparon de los asuntos públicos con plena entrega. Mientras que el resto de los espíritus quedan encadenados al retorno a la tierra, como en la teoría platónica, las almas de estos afortunados parten y regresan allí para morar eternamente («hinc profecti huc revertuntur»). ${ }^{16}$

Obviamente la idea de la inmortalidad celeste no es ni griega ni romana. Los pueblos orientales -egipcios, mesopotámicos, persas, etc.- sustentados

13. «Sed quo sis, Africane, alacrior ad tutandam rem publicam, sic habeto: omnibus, qui patriam conservaverint, adiuverint, auxerint, certum esse in caelo definitum locum, ubi beati aevo sempiterno fruantur; nihil est enim illi principi deo, qui omnem mundum regit, quod quidem in terris fiat, acceptius quam concilia coetusque hominum iure sociati, quae civitates appellantur; harum rectores et conservatores hinc profecti huc revertuntur.» Para la traducción hemos utilizado la de A. D’Ors, loc. cit.

14. Además, de otros libros platónicos pudo extraer parte de su concepción de la inmortalidad del alma, como el Fedón, 72 a. ss. y el Menón, 82 c. ss. Cf. P. BoyAncÉ, loc. cit., p. 128, n. 2 y p. 130. Cf. L. REY, «Propedéutica de M. T. Cicerón en torno a la trascendencia», Anuario Filosófico, 34, 2001, pp. 805-816.

15. Vid. Platón, Rep., 608-621. Macrobio, Comm., I, 8 y V, 1, ya se percató de este hecho. Cf. J. RAVENTós, loc. cit., pp. 22-24.

16. Vid. Macrobio, Comm., IX, 10 y XI, 8-10 cree que estas almas moran entre las estrellas en la última esfera, llamada aplanés, de la que habrían partido inicialmente y a la que regresarían por sus grandes merecimientos. Sobre la influencia platónica en Cicerón, y en general de la filosofía griega, cf. O. GiGON, «Cicero und die griechische Philosophie», NRH I, 1973, pp. 226-261. 
por conocimientos astrológicos de gran nivel científico, albergaron mucho antes creencias similares. ${ }^{17}$ Después, en Occidente, el pitagorismo desarrolló esta doctrina hasta el extremo de dotar a cada individuo de una parte corporal, condenada a desaparecer, y otra inmortal que moraría en los astros. ${ }^{18}$ Esta corriente, que se extendió con éxito por Roma y sus provincias, acabó siendo absorbida por otras creencias, como el platonismo y el estoicismo romanos. Ennio la habría expuesto ya en sus poemas y de ellos hizo uso Cicerón. ${ }^{19}$ Por otra parte, Plotino, ${ }^{20}$ según nos indica Macrobio, ${ }^{21}$ también destacaba cómo entre las cuatro virtudes que singularizaba, la primera era la política, bajo cuya protección los hombres justos se consagraban a gobernar por el bien de sus conciudadanos. Pero el influjo más intenso que recibió el arpinate en sus creencias sobre la trascendencia del alma le llegó a través de Panecio y Posidonio, este último su maestro, la figura capital de la corriente filosófica sincrética, que había conseguido a principios del siglo I a. C. la fusión entre el materialismo estoico y la inmortalidad celeste pitagórica. ${ }^{22}$ Otros autores menos importantes están también en la base del pensamiento ciceroniano, como Heráclides Póntico, Demetrio Falereo, Teofrasto, Dicearco, Polibio o Antioco de Ascalona, a los que hay que agregar las propias fuentes romanas, en especial, además del ya citado Ennio, Pacuvio, y la analística romana. ${ }^{23}$ Cicerón reflejó esta síntesis en su «De re publica», de donde derivó la creación de ese espacio sublime y restringido para las almas de los políticos, ${ }^{24}$ que es sin duda la parte más original del libro, en la que diverge del relato platónico, y que debió ser, muy probablemente, el motivo fundamental que le llevó a escribirlo. ${ }^{25}$ La originalidad del romano frente a Platón estriba en crear un área restringida, un «certus definitus locus». Nada hay tan romano en el «Somnium», tan ciceroniano, como esta parte. ${ }^{26}$ Sin embargo, entre el

17. F. Cumont, Lux Perpetua, París, 1949, p. 142 y ss.

18. F. Cumont, loc. cit., p. 146 y ss.

19. Cic., Tusc., IV, 1, 2 ss.; F. CUMONT, loc. cit., p. 151; P. BoyancÉ, loc. cit., p. 52.

20. Enead., I, 2.

21. Macrobio, Comm., VIII, 5.

22. Cf. G. Puente OjeA, Ideología e historia. El fenómeno estoico en la sociedad antigua, Madrid, 1974, p. 162.

23. Para las fuentes cf. A. Magariños, loc. cit., pp. 14-18; A. D’Ors, loc. cit., pp. 28-30; F. Cancelli, loc. cit., pp. 15-24; E. BrÉGuet, loc. cit., I, pp. 115-125; J. M. NúÑEz, loc. cit., pp. 26-29; P. BoyANCÉ,. loc. cit., p. 53 y n. 4.; P. Grimal, loc. cit., pp. 28-30; J. Guillén, Sobre...., pp. XX-XXI; I. Roca, op. cit., pp. 6164. Sobre la influencia estoica en Cicerón cf. G. VERBEKE, «Le stoïcisme, une philosophie sans frontières» ANRW I, 4, 1974, Berlín-Nueva York,, pp. 38-40. Acerca de la influencia de Platón y Polibio cf. J. HeURGON, «Platon, Cicéron et la République», Mél. Senghor, Dakar, 1977, 177-183. Sobre la influencia epicúrea cf. J. Kany-Turpin, «Cicéron lecteur d'Épicure», Revue Philosophique de la France et de létranger, 1, 1986, pp. 39-58. Acerca de la influencia pitagórica y el círculo de Nigidio Fígulo en Roma cf J. CARCOPINO, La Basilique pythagoricienne de la Porte Majeure, París, 1927. Una excelente visión global de las influencias de las diversas corrientes filosóficas en el pensamiento y en especial en la República puede consultarse en M. Morford, The Roman Philosophers. From The time of Cato the Censor to the death of Marcus Aurelius, Londres.Nueva York, 2002, pp. 33-92.

24. F. Cumont, loc. cit., pp. 162-163.

25. P. BoyAnCÉ, loc. cit., p. 139. En De senec. 83-84 Catón expresa su deseo de reunirse con su hijo difunto y con los grandes del pasado.

26. P. BOYANCÉ, loc. cit., p. 138. 
relato platónico de Er y el del arpinate subyace una clara coincidencia en la alta valoración que reciben las tareas públicas. Aunque Platón no les reserva un locus definido en el paraíso, sí resalta cómo una inadecuada actuación política está abocada al castigo, muy en especial cuando se contamina con la tiranía. ${ }^{27}$ El ejemplo platónico del tirano Ardieo, condenado a los peores castigos, es bien significativo a este aspecto. ${ }^{28}$ En Cicerón, no obstante, el relato se tiñe de optimismo, resaltando los premios frente a la utopía pesimista platónica. ${ }^{29}$

Para Cicerón esta morada privilegiada se localiza en la Vía Láctea. No se trata de una propuesta original. Diversos pensadores antiguos ya la habían elegido como lugar de acogida de las almas, ${ }^{30}$ dentro de teorías cosmológicas que desembocaron en el misticismo astral. ${ }^{31}$ Sin embargo, Cicerón no se conforma con imaginar un área restringida junto a las estrellas. Establece una condiciones para limitar el acceso solo a un grupo de personas escogidas (beati, meliores), aquellas que recibirán la gran recompensa celestial (tantum praemium) (VI \$24). El principio general es el de admitir a todos aquellos que han tutelado la res publica («...ad tutandam rem publicam»). La elección de los términos conduce a crear una similitud entre una institución de derecho privado, la tutela, y el ámbito de gobierno público. En la visión ciceroniana esa tutela solo era legítima cuando la situación general se encontrase en un estado de postración similar a la de un individuo, que sujeto al ius civile, presentaba una incapacidad temporal para obrar en plenitud de sus derechos. ${ }^{32}$ Con anterioridad Cicerón ya había tenido oportunidad de extenderse en esta idea a propósito del político que en un momento determinado debía acudir en socorro del estado, del que hablaba como un «bonus et sapiens et peritus utilitatis dignitatisque civilis, quasi tutor et procurator rei publicae» (II \$51). Naturalmente, entiéndese la res publica como el conjunto de instituciones que rigen al pueblo romano (populus), reguladoras de la convivencia entre todos sus miembros (I \$39). ${ }^{33}$

A continuación de este primer marco, Cicerón utiliza un elemento de refuerzo, que envuelve a la res publica de un tonalidad espiritual, el servicio a la patria: «omnibus, qui patriam conservaverint, adiuverint, auxerint...». El estilo de esta frase adopta el tono solemne de un precepto jurídico. ${ }^{34}$ La patria no es un simple sinónimo de la República. Para Cicerón, como para cualquier

27. Platón, Rep., 618.

28. Platón, Rep., 615.

29. A. Magariños, loc. cit., p. 13-14; M. Morford, loc. cit., p. 67. Como diría P. Boyancé, loc. cit., p. 173, «si les sentiments sont bien romaines, les idées sont toutes grecques».

30. Para estos autores cf. P. Boyancé, loc. cit., p. 133-137.

31. Cf. A. Le Boeuffle, Le ciel des romaines, París, 1989, pp. 113-135. La expresión ciceroniana orbis lacteus deriva de Aristóteles y Ptolomeo, que pensaban que la Vía Láctea tenía una forma circular. Cf. J. Guillen, loc. cit, p. 130, n. 9.

32. Vid. Dig. 26. 1. 1 la definición clásica de Servio Sulpicio Rufo: «vis ac potestas in capite libero ad tuendum eum qui propter aetatem sua sponte se defendere nequit, iure civili data ac permissa». Sobre estas figuras cf. A. D’Ors, Derecho privado romano, Pamplona, 1981, pp. 355-366.

33. Sobre estos conceptos cf. I. RocA, op. cit., pp. 33-34.

34. Cf. P. BoyAncé, loc. cit., p. 138. 
romano, tiene un sentido sagrado por estar vinculado a la idea de la sumisión que se debe a los parentes, léxico con el que entronca etimológicamente, y el cual en un momento determinado se transfirió al estado romano. Esto hace que todo servicio público quede asociado a un deber religioso, la pietas, que envuelve para un romano los sagrados deberes con la familia y con los dioses. ${ }^{35}$ Para Cicerón las obligaciones con los padres se igualan así con las que deben rendirse a sociedad. ${ }^{36} \mathrm{El}$ patriotismo es la fidelidad a la tradición, a aquello establecido por los ancestros, y que se apoya, por consiguiente en el Senado, los padres de la comunidad (patres et conscripti). El pius es tanto un patriota como un conservador del orden heredado de los mayores. ${ }^{37}$ Es obvio que Cicerón sentía un orgullo muy especial por haber aplicado ese patriotismo en el auxilio que había proporcionado a la República durante los sucesos de la conjuración de Catilina. ${ }^{38}$ Para Cicerón son tres los servicios máximos que se pueden prestar a la patria: conservación (conservare), ${ }^{39}$ asistencia (adiuvare) ${ }^{40}$ y engrandecimiento (auxere).$^{41}$ El servicio a la patria permite, pues, que el alma llegue más rápidamente al cielo: «Ejercita tú el alma en lo mejor, y es lo mejor los desvelos por la salvación de la patria, movida y adiestrada por los cuales, el alma volará más velozmente a esta sede y propia mansión.» (VI \$26). ${ }^{42}$

Finalmente, el texto ciceroniano establece una última condición, que acota definitivamente los requisitos exigibles a todos los que aspiran a la gran recompensa. Aquello, afirma, que el dios supremo (princeps deus, numen) ve con mayor favor son las ciudades (civitates) por tratarse de una agrupación de hombres unidos por el vínculo del derecho («concilia coetusque hominum iure sociati»), es decir, por una ciudadanía común. ${ }^{43}$ Los dirigentes de las ciudades son, por tanto, los emplazados a la suprema bienaventuranza celestial. Cicerón, sin embargo, distingue entre ellos dos tipos: los que presiden sus gobiernos (rectores) y los que las salvaguardan de peligros (conservatores). Se advierte por el vocabulario empleado que hay un intento deliberado por evitar precisiones institucionales. Los rectores et conservatores no existen como cargos en las ciudades, son en un sentido genérico todos los gubernatores civitatis (II, $\$ 29$

35. Cf. J. HellegouarC'H, Le vocabulaire latin des relations et des partis politiques sous la République, París, 1972, p. 276.

36. Cic., VI \$16: «Iustitiam cole et pietatem quae cum magna in parentibus et propinquis, tum in patria maxima est.»

37. Cf. J. Hellegouarc'H, loc. cit., p. 278.

38. Cf Boyancé, loc. cit., p. 138. Con el tiempo el emperador fue el amo del Imperio como Dios es el amo del mundo. Una idea estoica y neopitagórica. Ibidem pp. 141-143.

39. Vid. T.L.L, s.v. conservo, cols. 419-422. Cf. P. BoyANCÉ, loc. cit., p. 138, n. 4., lo vincula incluso a la salvaguardia del estado.

40. Vid. T.L.L, s.v., adiuvo, col. 718 y ss.

41. Vid. T.L.L, s.v., augeo, col. 1354, 13-14.

42. "Hanc tu exerce optimis in rebus! Sunt autem optimae curae de salute patriae, quibus agitates et exercitatus animus velocius in hanc sedem et domum suam pervolabit.»

43. Cf. P. Rodríguez, «El significado de civitas en Cicerón», Veleia, 7, 1990, pp. 233-241. Obsérvese que concilia tiene el sentido de «asamblea convocada», mientras coetus vendría a ser una «reunión voluntaria de hombres». Vid. A. MAgariños, loc. cit., p. 38. 
y 51). ${ }^{44}$ Dentro de los primeros pueden ser englobados holgadamente tanto los magistrados como los miembros de las asambleas legislativas de carácter permanente (curia, senatus). ${ }^{45}$ Asimismo, entre los conservatores podrían tener cabida los protectores del estado en un momento dado, ${ }^{46}$-incluso en sus ritos religiosos $-{ }^{47}$ y cualquier defensor o filántropo de la ciudad (patroni, evergetas). ${ }^{48}$ Así pues, Cicerón establece un paralelismo entre la divinidad suprema, que rige el mundo, y los políticos que dirigen las ciudades. ${ }^{49}$ Dos planos, sensorial y suprasensorial, que se enlazan tras la muerte. El cursus honorum de los senadores finaliza, de este modo, en el más allá. Cicerón había alcanzado la gloria personal en su época del consulado y su victoria ante Catilina, como un Rómulo refundador de Roma, un salvador de la ciudad, o como un miembro de la saga escipiónica, le permitía modelar su figura en el plano de los grandes héroes..$^{50}$

A buen seguro el pensamiento del arpinate ha tomado de la teología estoica de un discípulo de Zenón, Perseo, la concepción de que los héroes benefactores de la humanidad alcanzan la divinidad, formando una categoría especial de dioses, la séptima. ${ }^{51}$ Intelectualmente enlaza con una tradición pitagórica y aristotélica de origen helenístico, que exalta a la divinidad a héroes mitológicos famosos (Hércules, Dioscuros, Dionisos, Esculapio, etc.), ${ }^{52}$ muchos de los cuales se convirtieron en parte de las constelaciones en la literatura astronómica. ${ }^{53}$ No es la única vez que repetirá esta concepción ${ }^{54}$ que naturaliza plenamente pues la remonta nada menos que hasta las leyes más arcaicas romanas, como las de las XII Tablas y las leges sacratae. ${ }^{55}$ Tampoco a Macrobio se le pasó por alto que estas fuentes pudieron influir en el ideario de Cicerón, al citar cómo Hesíodo ya situaba a los antiguos reyes entre los dioses, que desde el cielo regían las cuestiones humanas. ${ }^{56}$ Los grandes hombres en

44. También primores civitatis. Vid. Tac., Ann., I, 8, 1-2.

45. Vid. Liv. 4, 14, 2, refiriéndose al dictador Cincinato como rector rei publicae.

46. Cicerón utiliza en otros escritos también la variante conservator rei publicae. Vid. Vat., 7; Phil., 2, 31, 51; 3, 8, 14; De leg., 2, 6; Vell. 2, 66, 3; Quint. 9, 3, 86.

47. Vid. Cic., De leg., 2, 42, como conservator de los principios religiosos de la comunidad. Cf. F. PINA, «Cicerón, elegido de los dioses: La reprobación religiosa del adversario político como recurso retórico», en Religión y propaganda política en el mundo romano, Instrumenta 12, p. 65.

48. L. HARMAND, Le patronat sur les collectivités publiques des origines au Bas Empire. Un aspect social et politique du monde romaine, Clermont, 1955.

49. P. BoyAnCÉ, loc. cit., p. 141.

50. Cic., Cat., III 2. Cf. F. Pina, loc. cit., pp. 211-212. Cf. M. VAlencia, «Cicerón creador de su imagen política: Fam., V, 12», Faventia, 19, 1, pp. 19-20. Vid. también J. P. MARTin, Providentia deorum. Aspects religieux du pouvoir impérial romaine, Roma, 1982, p. 50.

51. De nat. deor., I, 15, 38.

52. P. BOYANCE, loc. cit., p. 145

53. J. A. GonzÁLEZ-C. ReAL, «Interpretación mítica del firmamento: de Cicerón a San Isidoro», Cuad. Filol. Clás. Estudios Latinos, 2000, 19, pp. 35-52.

54. Tusc., I, 12, 27-28; De nat. deor., I, 15, 38; II, 24, 62.

55. De leg., II, 8, 19.

56. Vid. Macrobio, Comm. I, 9. Cf. Hesiod., Los trabajos y los días, pp. 122-123 y p. 126. También Manilio I, 578 y ss., escritor del tiempo de Augusto, enumera hombres públicos griegos y romanos que habitan la Vía Láctea, entre estos últimos Scipiadae duces, fatum Carthaginis unum ... Aemiliaeque domus proceres. Cicerón y Manilio pudieron tomar estas ideas de Heracleides del Ponto. Cf. A. MagARIÑos, loc. cit., p. 38. 
la concepción ciceroniana tienen un destino diferente tras la muerte a la del resto de los mortales: mientras las almas de estos son simplemente inmortales, las de los benefactores, rectores et conservatores, son divinas. ${ }^{57}$ Sus intentos por garantizar la inmortalidad de su hija Tulia, construyéndole un fanum y ofreciéndole una apoteosis, son bien elocuentes con relación a esta diferencia. ${ }^{58}$

Cicerón, pese a asociarse tan fielmente al pensamiento de Platón, lo dota de un sentido nuevo al trasladarlo a la realidad romana. Como cabía esperar, el filósofo griego circunscribe el ejercicio del servicio público al mundo de las póleis. La ciudad griega es el marco político supremo, que actúa como un estado soberano, en donde, según Platón, es el sabio quien debe gobernar para garantizar la justicia al pueblo y, a cambio, ser quien se haga merecedor de los elogios reservados a los grandes hombres. ${ }^{59}$ La Roma de Cicerón nada tiene que ver con la atomización que presentaban las póleis helenas en tiempo de Platón y que marcan el horizonte de su concepción. Es cierto que desde su nacimiento Roma se configura como una comunidad de ciudadanos (cives). La pertenencia a la ciudad, patria y solar común de sus individuos, estrechamente ligados por lazos comunes de ciudadanía, regidos por una instituciones y prácticas establecidas por los antepasados (mos maiorum) y bajo la suprema soberanía de los dioses (religio), fue el factor esencial que le dio una admirada robustez. La ley decenviral primero, y después las restantes que fueron desarrollándose a lo largo de la vida de la República, reconocía al ciudadano un amplio conjunto de derechos y deberes. Entre ellos el ius honorum, el derecho a detentar las magistraturas del estado. Durante muchos años las familias patricias, concentradas en un número determinado de gentes, acapararon los puestos dirigentes y restringieron la participación de la plebs, que solo con una violenta y prolongada lucha consiguió arrebatarles lenta y escalonadamente. A principios del siglo III a. C., salvo en algunas excepciones de escasa importancia, los plebeyos habían conseguido culminar sus aspiraciones integradoras. Otra cosa es que el fuerte componente aristocrático de la sociedad romana favoreciera que las instituciones del estado quedaran en manos de la nueva nobilitas patricio-plebeya. Entre sus miembros se reclutaban los magistrados que dirigían la República y, de forma colectiva, de ellos se nutría la importante cámara senatorial. Durante generaciones conservaron el poder, sin un beneficio material tangible, compensados por el poder que les daban sus magistraturas y la auctoritas perpetua que les reportaba haberlas ejercido. Cuando un noble fallecía su entierro constituía un acto de reconocimiento público de sus servicios y, a su vez, de los de su familia, que se manifestaba en la categoría de

57. De leg., II 11, 27-28. Cf. J. P. Martin, loc. cit., p. 61.

58. Cons. F 16 = Tusc. III, 76; Att., XII, 15, 1. A este respecto cf. P. BoyanCÉ, «L'apothéose de Tullia», REA, 1994, 46, pp. 179-184; Y. G. LEPAGE, «Cicéron devant la mort de Tullia d'après sa correspondance», LEC, 1976, 44, pp. 245-258; J. MuÑIz, «Cicerón y el santuario de Tulia. Teoría religiosa y práctica financiera», Arys, 1, 1998, 119-137; A. SETAIOLI, «El destino del alma en el pensamiento de Cicerón (con una apostilla sobre las huellas ciceronianas en Dante)», Anuario Filosófico, 2001, 34, pp. 487-526, esp. p. 517.

59. Platón, Rep., 412-417 y 473. 
las honras públicas que recibía.$^{60}$ Esta era la República que Cicerón añoraba. ${ }^{61}$ Pero la realidad se alejaba cada vez más de este pasado. El sistema político y los valores que la arropaban sufrieron el impacto de la prodigiosa expansión territorial que desembocó en la conquista del mundo mediterráneo. El paso de la civitas a la oikumene, de urbe a orbe, destruía implacablemente un régimen incapaz de adaptarse. ${ }^{62}$ Para un personaje como Cicerón, un agradecido homo novus, ${ }^{63}$ la República que le había permitido incorporarse al estamento superior de los senadores, vivificado por la pequeña nobleza italiana ecuestre y municipal que la ley Plautia-Papiria habría incorporado en el 89 a. C., aún podía salvarse. ${ }^{64}$ Los hombres más esforzados podrían, estimulados por la gran recompensa, como él mismo había tenido la oportunidad de demostrar siendo cónsul, reconducir el rumbo de la patria hasta llevarla a buen puerto sin perder su libertas y sus tradiciones: ${ }^{65}$

Ahora yo, Africano, puesto que está abierto lo que llamaríamos acceso del Cielo a los beneméritos de la patria, aunque no os hice deshonor siguiendo desde joven las huellas de mi padre y tuyas, voy a esforzarme con mucha mayor diligencia a la vista de tan gran premio. (VI 24) ${ }^{66}$

Después de Farsalia la realidad se tornó sombría para los ideales de Cicerón. Era evidente que el estado estaba en manos de un hombre que se servía de él sin ningún miramiento. Callada, inexorablemente, la monarquía iba afirmándose cada vez más. Ocupado en sus labores literarias, en las que se había enfrascado

60. Polib., VI, 53-54.

61. Cf. G. Boissier, loc. cit., pp. 26-44; P. BAdillo, loc. cit., p. 27-29. Sobre la concepción ciceroniana de la historia cf. C. CARrasco, «El camino hacia una constitución ideal: la Res Publica romana (Decenvirato y Res Publica como constitución mixta: Polibio y Cicerón)», ILAS, 2004, pp. 3-16.

62. Sobre la crisis de la república cf. A. SuArez, La crisis de la república romana (133-44 a. C.): La alternativa política de los populares, Verín-Santiago, 2004.

63. Cf. J. Béranger, «Les jugements de Cicéron sur les Gracques», $A N R W$ I, 1, 1972, Berlín-Nueva York, pp. 732-763.

64. C. Nicolet - A. Michel, Cicéron, París, 1961, p. 59; J. Gulllén, Héroe..., p. 119. Sobre los homines novi y sus ideales republicanos cf. C. BALmACEDA, «Virtus romana en el s. I a. C.», Gerión, 25, 2007, pp. 285-304. Para el caso concreto de Cicerón cf. R. Syme, The Roman revolution, Oxford, 1990, pp. 11, 13, 89 y 94; E. S. GRuen, The Last Generation of the Roman Republic, Berkeley-Los Angeles-Londres, $1995^{1}$, pp. 137-141; F. Pina, loc. cit., p. 11-12 y 103-106. Sobre el concepto de ciudad de Cicerón cf. L. Storoni, L’idea di città nel mondo romano, Florencia, 1994, p. 48. Vid. F. Pina, loc. cit., pp. 247 y ss.; M. VAlencia, op. cit., p. 26. Para la visión de renovatio temporum ciceroniana cf. C. MoATti, «Tradition et raison chez Cicéron: l'émergence de la rationalité politique à la fin de la république romaine», de l'École Française de Rome. Antiquité, 100, 1988, pp. 385-430.

65. Cf. J. DAzA, «Ius, libertas, civitas en Cicerón», Estudios en homenaje al profesor F. Hernández-Tejero, Madrid, pp. 1992 (1994), pp. 97-110. También C. H. Wirszubski, Libertas. As a political idea at Rome during the Late Republic and Early Principate, Cambridge, 1968; F. Öktem, «Libertas in Cicerone», D. T. C. Fakültesi Dergisi, 33, 1990, pp. 365-374. Sobre el concepto de libertas como expresión del monopolio de la nobleza cf. F. De Martino, Storia de la Costituzione Romana, IV, Nápoles, 1962, p. 3. Para la obra de Cicerón en el marco de la decadente república cf. A. Lintotт, The Constitution of Roman republic, Oxford, 1999, pp. 220-232.

66. «Ego vero, inquam, Africane, siquidem bene meritis de patria quasi limes ad caeli aditum patet, quamquam a pueritia vestigiis ingressus patris et tuis decori vestro non defui, nunc tamen tanto praemio expositio enitar multo vigilantius.» 
huyendo del presente, Cicerón recibió con satisfacción la noticia de la muerte de Cesar. La esperanza de que por fin hubiera llegado el tiempo del ansiado renacimiento político le impulsó a regresar a la vida pública. Unido al joven Octaviano desencadenó una feroz campaña contra Marco Antonio que le dio la falsa impresión de que la República se afirmaba nuevamente. Pero fue una creencia que se desvaneció bien pronto. La conclusión de una interesada alianza entre el joven Cesar Octaviano y Marco Antonio desencadenó una feroz campaña de proscripciones, de la que Cicerón fue una de sus primeras víctimas.

¿Qué iba a quedar de la gran promesa? Aunque resulte paradójico, el nuevo régimen que tras la derrota de Marco Antonio en el 31 a. C. quedó firmemente establecido en manos de Octavio, y que tanto había tenido que ver en sus inicios con la desaparición de Cicerón y la censura durante años de sus escritos, ${ }^{67}$ utilizó sin complejos su ideario ${ }^{68}$ La figura del tutor rei publicae ahora era convenientemente transformada en una suerte de cura et tutela rei publicae ${ }^{69}$ al servicio de un princeps ávido por concentrar todos los poderes en su persona, que poco tenía que ver con el desinteresado patriota que imaginara el arpinate y que transformaron el régimen en una monarquía. ${ }^{70}$ Por otra parte, los epítetos Iulia y Augusta, a los que el paso de los años se añadieron los de Claudia, Sulpicia, Flavia..., acompañaron los nombres de las nuevas ciudades. ${ }^{71}$ Los emperadores son de aquí en adelante los verdaderos, los únicos rectores ${ }^{72}$ y conservatores ${ }^{73}$ del mundo romano.

Arrebatada la gloria terrenal, ¿cuál iba a ser el destino del locus supra terreno? Tampoco en este terreno los emperadores iban a tolerar que tan excelso lugar pudiera serles disputado. La divinización imperial introdujo un factor nuevo que alteraba la construcción celeste de Cicerón. Primero fue la divinización de Cesar en el 42 a. C., después de la aparición de un cometa el año de su muerte al que el pueblo creía la personificación de su alma, confirmada en el 29 a. C. con la dedicación de un templo a su persona en el foro. Más tarde le siguieron las deificaciones de Augusto, Claudio, Vespasiano,

67. Plut., Cic., 49, 5. Sobre la relegación de su obra cf. J. CARCOPIno, loc. cit., I, p. 33 y ss; G. Boissier, loc. cit., p. 239; cf. C. Nicolet - A. Michel, loc. cit., p. 178; P. L. SCHMidt, op. cit., pp. 262-333.

68. Cf. P. Grimal, loc. cit., pp. 119.

69. Sobre este tema cf. el polémico A von Premerstein, Vom Werden und Wesen des Prinzipats, Munich, 1937, p. 137 y ss. Cf A. Magariños, loc. cit., pp. 10-11.

70. Vid. F. PinA, loc. cit., p. 265-266. Para la aceptación del mismo por un estoico como Séneca cf. I. MuÑoz, «La concepción del imperio romano como principado», Cuadernos de filología clásica, 4, 1972, pp. 115-125.

71. Cf. B. Galsterer-Kröll, «Untersuchung,en zu den Beinamen der Städte des Imperium Romanum», Epigraphischen Studien, 9, 1972, pp. 44-145.

72. Como ejemplos del uso de estos terminus por los emperadores vid. Ovid., Trist., 2, 3: rector dicare paterque; Plin., N. H., II 18: maximus omnis aevi rector Vespasianus; Tac., Ann., III 59: rectorem generis humanis.

73. Vid. E. De Ruggiero, Dizionario Epigrafico di Antichità Romane, Roma, 1971, p. 609, que recoge, como epítetos de los emperadores, los siguientes: conservator patriae, caeremoniarum publicorum et restitutor aedium sacrarum; conservator pacis Augustae; conservator generis humanis; conservator rei publicae et omnium provincialium. 
Tito... La implantación del culto imperial aseguró a los emperadores la categoría de dioses y su expansión por las provincias fortaleció su fidelidad al estado.$^{74}$ La divinización imperial era escenificada en la apoteosis o consecratio - opuesta a la damnatio memoriae de los malos emperadores- que suponía la transformación de sus almas en astros o, en todo caso, su partida a un lugar muy próximo a los mismos. ${ }^{75}$ Un águila era liberada en el momento de los funerales para que llevase el alma del príncipe. La domus augustea -pues también se incorporó la emperatriz y la familia imperial- desplazaba de aquí en adelante el locus privilegiado que había configurado Cicerón para las almas de los beati republicanos. ${ }^{76}$

Solo cuando finaliza el despotismo en que habían desembocado las dos primeras dinastías imperiales, con las atroces tiranías de Nerón y Domiciano, nos llega algún eco del viejo pensamiento ciceroniano, acaparado desde hacía lustros por los emperadores. Cien años después Tácito, de forma vacilante, se interrogaba sobre la existencia de un locus empíreo para las almas grandes (magnae animae), lo que demuestra que aún era leído por un público selecto y estudiado en las escuelas de retórica: ${ }^{77}$ «Si existe un lugar para los manes de los justos, si como piensan los filósofos las almas excelsas no se extinguen con el cuerpo, descansa en paz... $\gg^{78}$ Vana esperanza. Ya no son los servicios políticos a la república los que les abrirán las puertas del cielo a los nobiles romanos. El acceso directo era desde hacía años para los buenos emperadores y eran ellos los que, en todo caso, podían ayudar a franquearlo a quienes mejor les hubieran servido. Y estos no eran ya los senadores. Los arcanos de la supervivencia del Imperio estaban en el ejército. Es en este marco como podemos entender las palabras del futuro emperador Tito a sus soldados ante las murallas de Jerusalén:

Yo, por mi parte, dejo a un lado el elogio de la muerte en la guerra y la inmortalidad de los que caen por el furor bélico, y desearía que los que piensan de otra forma murieran de enfermedad en tiempo de paz, ya que su alma está condenada a permanecer en la tumba junto con su cuerpo. ¿Qué hombre valiente no sabe que las almas que han sido separadas de la carne por el hierro en la lucha son acogidas por el éter, el más puro de los elementos, que las coloca entre los astros, y que se convierten para la posteridad en genios

74. Sobre el culto imperial, sus orígenes y desarrollo, cf. D. FISHwICK, The imperial cult in the Latin West, Leiden, 1987, I 1, pp. 46 y ss; sobre la consecratio imperial cf. J. ArCE, Funus imperatorum. Los funerales de los emperadores romanos, Madrid, 1988, pp. 129-140.

75. Plin., Paneg., 89, 2. Para los temas de divinización y consecratio cf. J. Prieur, La mort dans l'antiquité romaine, La Guerche-de-Bretagne, 1986, pp. 138-148.

76. Cf. J. P. MARTin, loc. cit., pp. 75-76 y 82-89.

77. La influencia en la Eneida VI, 640-655 ya fue destacada por Macrobio (I, 9, 8-9). Séneca está plagado de este tipo de pensamientos. Cf. Cons. Hel., 8, 4; Epist. Luc., 93, 9; 117, 19. Sobre su influencia en Plinio, Aulo Gelio, Tácito, Quintiliano y Frontón cf. E. J. KenNey - W. V. Clausen (ed.), loc. cit., II, p. 300 y E. BrÉguet, loc. cit., pp. 162-163. Para su huella en Marco Aurelio cf. P. Boyancé, loc. cit., p. 156.

78. «Si quis piorum manibus locus, si, ut sapientibus placet, non cum corpore exstinguuntur magnae animae, placide quiescas...». Tac., Agric., 46, 1. 
buenos y héroes bienhechores. Mientras que las almas que se consumen a la vez que sus cuerpos enfermos, aunque no tengan manchas ni impurezas, la noche subterránea acaba con ellas y un profundo olvido las recibe, de modo que así consiguen a la vez la desaparición de su vida, de su cuerpo y también de su recuerdo. Si el Destino ha fijado para el ser humano una muerte irremediable y el hierro es mejor verdugo para ella que cualquier enfermedad, ¿cómo no va a ser una cobardía negar al bien común lo que debemos pagar por necesidad? He dicho estas palabras como si las personas que intentaran esta hazaña no pudieran salvarse; sin embargo, a los hombres valientes les es factible librarse incluso de los peores peligros... Me avergonzaría si a aquel que escalara el primero no lo convirtiera yo en una persona envidiable por las recompensas que le voy a dar: el que sobreviva será el jefe de sus iguales y los que mueran recibirán las más dichosas recompensas. ${ }^{79}$

Qué mejor prueba de que los tiempos habían cambiado. Escipión tuvo un sueño y a Cicerón, su portavoz, se lo habían arrebatado.

79. Flavio Josefo, La guerra de los judios, VI, 46-53. Traducción de J. Mª NiETo, Biblioteca Clásica Gredos, Madrid, 1997, pp. 253-255. 